\title{
Aortic arch reconstruction with pulmonary autograft patch aortoplasty
}

Régine Roussin, $\mathrm{MD}^{\mathrm{a}}$

Emre Belli, MD ${ }^{a, b}$

François Lacour-Gayet, MD

Francois Godart, MDc

Christian Rey, MDc

Jacqueline Bruniaux, MD

Claude Planché, MDa

Alain Serraf, MDa
From the Department of Pediatric Cardiac Surgery, Marie Lannelongue Hospital, Le Plessis-Robinson, France, ${ }^{\mathrm{a}}$ Department of Pediatric Cardiac Surgery, Deutsches Kinderherzzentrum, Sankt Augustin, Germany, ${ }^{\text {b }}$ and Department of Pediatric Cardiology, University Hospital, Lille, France. ${ }^{c}$

Read at the Eighty-first Annual Meeting of The American Association for Thoracic Surgery, San Diego, Calif, May 6-9, 2001

Received for publication May 14, 2001; revisions requested June 22, 2001; revisions received July 24, 2001; accepted for publication Sept 7, 2001.

Address for reprints: Alain Serraf, MD, Pediatric Cardiac Surgery, Marie Lannelongue Hospital, 133, Avenue de la Résistance, 92300, Le Plessis-Robinson, France.

J Thorac Cardiovasc Surg 2002;123:443-50

Copyright (C) 2002 by The American Association for Thoracic Surgery

0022-5223/2002 $\$ 35.00+0 \quad \mathbf{1 2 / 6 / 1 2 0 7 3 3}$

doi:10.1067/mtc.2002.120733
Objective: The optimal technique for aortic arch reconstruction through median sternotomy is still under debate. We have introduced the technique of pulmonary autograft patch aortoplasty as a reliable alternative.

Methods: The outcomes of 51 infants who underwent neonatal repair of interrupted aortic $\operatorname{arch}(n=28)$ or coarctation associated with ventricular septal defect $(n=23)$ since 1992 were analyzed. The patients were reviewed in three groups according to the aortic arch reconstruction technique: group I underwent direct anastomosis $(\mathrm{n}=$ 23 ), group II underwent homograft or pericardial patch aortoplasty $(n=8)$, and group III underwent pulmonary autograft patch aortoplasty $(n=20)$. The pulmonary autograft patch consisted in the anterior wall of the main pulmonary artery, between the supracommissural level and the divided ductus arteriosus. The created defect was replaced with fresh autologous pericardium.

Results: All patients except 1 were discharged without significant residual gradient at the level of the aortic arch. At a median delay of 7 months (range 2-51 months), 11 patients $(22 \%)$ had recurrence of arch obstruction and underwent balloon angioplasty $(n=8)$ or surgical correction $(n=3)$. One patient who had undergone direct anastomosis required reoperation for bronchial compression. At a median follow-up of 29 months, the actuarial freedoms from recurrent arch obstruction were $81 \%$ for direct anastomosis, $28 \%$ for homograft or pericardial patch aortoplasty, and $100 \%$ for pulmonary autograft aortoplasty $(P=.03$ for group III vs group I and $P<.0001$ for group III vs group II).

Conclusions: The aortic arch repair associated with pulmonary autograft patch augmentation resulted in superior midterm outcomes and therefore constitutes a reliable alternative to the direct anastomosis technique. It allowed complete relief of anatomic afterload and diminished the anastomotic tension, thus reducing the risk of restenosis and tracheobronchial compression. We observed a significantly higher rate of recurrence after patch aortoplasty with other materials.

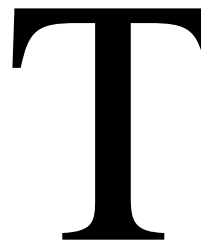

he surgical experience of the last decade has allowed us to evaluate the advantages of single-stage biventricular repair of aortic arch obstruction and associated intracardiac defects during the neonatal period. ${ }^{1-4}$ However, debate continues regarding the method of aortic arch reconstruction itself. Resection and primary anastomosis constitutes the most commonly used technique, with a rate of recurrence varying between $5 \%$ and $25 \%$ according to reported series. ${ }^{5-8}$ To avoid recurrence, patch augmentation of the aortic arch (and when necessary the ascending aorta) has been proposed as an alternative. ${ }^{4,9,10}$ Homograft, xenograft, and synthetic materials 


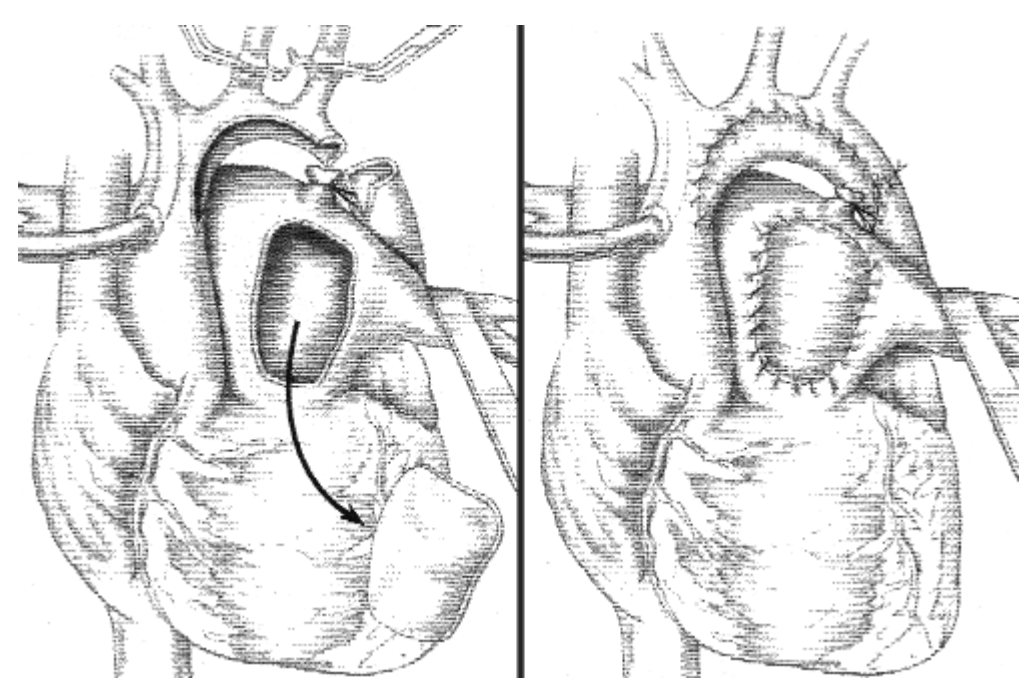

Figure 1. Drawing representing aortic repair technique by means of pulmonary autograft patch augmentation.

TABLE 1. Patient groups

\begin{tabular}{lcccc}
\hline & $\begin{array}{c}\text { Group I } \\
(\mathbf{n = 2 3})\end{array}$ & $\begin{array}{c}\text { Group II } \\
(\mathbf{n = 8})\end{array}$ & $\begin{array}{c}\text { Group III } \\
(\mathbf{n = 2 3 )}\end{array}$ & $\begin{array}{c}\text { Total } \\
(\mathbf{n = 5 4})\end{array}$ \\
\hline IAA and VSD & 15 & 3 & 12 & 30 \\
Type A & 3 & 0 & 0 & 3 \\
Type B & 11 & 2 & 11 & 24 \\
Type C & 1 & 1 & 1 & 3 \\
Coarctation and VSD & 8 & 5 & 11 & 24 \\
\hline
\end{tabular}

Group I underwent repair by direct anastomosis, group II with a pulmonary homograft patch $(n=4)$ or a xenopericardial patch $(n=4)$, and group III with a pulmonary autograft patch.

have been used. The patch augmentation technique with biologic materials has also resulted in a considerable rate of recurrence. However, the use of synthetic patches in neonates presents technical difficulties, and the late development of aortic aneurysm is common. ${ }^{11}$

Pulmonary autograft patch aortoplasty is an easy and reproducible technique that permits aortic arch augmentation by means of a viable tissue patch. It has been used since 1997 in combination with resection and end-to-end anastomosis for the treatment of interrupted aortic arch (IAA) as well as coarctation. This article reports a retrospective comparative analysis of our recent experience with different techniques, with particular attention to the outcome of the reconstructed aortic arch.

\section{Patients and Methods \\ Patients}

The study cohort consisted of 54 consecutive patients operated on between January 1992 and December 2000. Six of the patients were operated on by one of the authors (E.B.) at a second institution. All patients except 1 underwent single-stage biventricular repair for aortic arch obstruction and associated intracardiac defects. Only patients operated on during the neonatal period $(<30$ days after birth, $n=49$ ) and patients with ductus-dependent lower body perfusion beyond the first month of life $(n=4)$ were included in this study. Patients with associated transposition of the great arteries or truncus arteriosus and those for whom a univentricular palliation was expected were not included. The median age at operation was 12 days (range 3-81 days), and the median weight was $3.1 \mathrm{~kg}$ (range 2-4 kg). Prostaglandin $\mathrm{E}_{1}$ administration was necessary for 29 patients. Six patients were critically ill, requiring ventilatory support, and 7 patients received inotropic support. Di George syndrome was diagnosed in 14 cases. All patients were evaluated preoperatively by echocardiography. Cardiac catheterization was performed in 6 cases. The anatomic features of the aortic arch and the site of interruption were determined according to the classification of Celoria and Patton. ${ }^{12}$ There were 30 cases of IAA associated with ventricular septal defect (VSD) and 24 cases of coarctation associated with VSD (double-outlet right ventricle in 1 case; Table 1). The coarctation was associated with aortic arch hypoplasia in most cases $(\mathrm{n}=21,88 \%)$, with the mean diameter of the aortic arch being $2.9 \pm 0.6 \mathrm{~mm}$. The associated lesions were 18 cases of subaortic stenosis, ${ }^{2} 3$ cases of multiple VSDs, 1 case of aortopulmonary window, 1 case of left pulmonary artery arising from the aorta, and 1 case of left atrial isomerism. VSDs were perimembranous $(n=41)$, muscular $(n=6)$, or infundibular $(n=4)$.

\section{Surgery}

The technical approaches for arch reconstruction started from the same principles, the systematic resection of all ductal tissue and extensive mobilization of the descending aorta. A direct anastomosis between the two aortic segments was performed in 23 cases (group I). In the presence of IAA the descending aorta was anastomosed end-to-side to the lateral aspect of the distal part of the ascending aorta. In cases of coarctation the previously described 
extended end-to-end repair was performed. ${ }^{13}$ In the remaining 31 cases, after incision of the lateral aspect of the ascending aorta and the concavity of the aortic arch proximal to the resected coarctation, an end-to-side anastomosis (in cases of IAA) or extended end-toend anastomosis (in cases of coarctation) was done in all cases by leaving around a third of the most proximal anastomosis open (Figure 1,A). The medial aspect of the descending aorta was incised 15 to $20 \mathrm{~mm}$ distal to this anastomosis. The defect was then augmented with a pulmonary homograft patch $(n=4)$ or a xenopericardial patch $(n=4)$ in 8 cases (group II). In the study technique, the defect was augmented with a pulmonary autograft patch (group III, $\mathrm{n}=23$; Figure $1, B)$. In 3 neonates with coarctation and severe arch hypoplasia $(<3 \mathrm{~mm})$, after ligation of the isthmus the descending aorta was anastomosed end-to-side to the ascending aorta-proximal arch junction, and that join was augmented with the pulmonary autograft patch. ${ }^{14}$ The size and also the elasticity of the pulmonary autograft patch permitted adequate augmentation of the aortic arch in all cases. In cases of ductus-dependent lower body perfusion, the main pulmonary artery is by definition dilated. The pulmonary autograft patch consisted of the anterior wall of the main pulmonary artery, between the supracommissural level and the ligated ductus arteriosus. Harvesting of the autograft patch started at the proximally situated pulmonary arterial cannulation site. Particular attention was paid to staying at a distance from both pulmonary artery branches' ostia. The created defect in the main pulmonary artery was replaced with a xenopericardial patch in 2 cases at the beginning of the experience and by fresh autologous pericardium in the last 20 cases (Figure $1, B$ ). The pulmonary artery was directly closed in 1 case because of its large size.

The aortic arch repair was performed with the patient in deep hypothermic circulatory arrest in 32 cases; the remaining 22 patients $(38 \%, 70 \%$ confidence interval $[\mathrm{CI}] 31 \%-46 \%)$ were operated on with continuous cardiopulmonary bypass and hypothermia but without total circulatory arrest. ${ }^{15}$ During arch reconstruction the extremity of a malleable arterial cannula (model 77008; Medtronic DLP, Grand Rapids, Mich) was introduced into the innominate artery; the innominate artery was snared, and the flow was diminished by around $50 \%$ to maintain a mean arterial pressure of 30 to $40 \mathrm{~mm} \mathrm{Hg}$. The median aortic crossclamp time was 63 minutes (range 27-182 minutes), the median cardiopulmonary bypass time was 130 minutes (range 90-317 minutes), and for the 32 patients for whom a period of total circulatory arrest was done the median circulatory arrest time was 31 minutes (range 18-95 minutes). The intracardiac repair was performed by previously described techniques for each specific malformation. The left ventricular outflow tract was examined. Eighteen patients had evidence of subaortic stenosis. Subaortic myotomy or myectomy was performed only in 3 cases. Among the 2 other cases with a virtually occluded subaortic region, biventricular repair was achieved by a Ross-Konno procedure in 1 case; the other patient underwent a Damus-Kaye-Stansel and Rastelli operation. The subaortic narrowing was ignored in the remaining 13 cases. The VSD was closed through the right ventricle in 37 cases, the right atrium in 10 cases, and the pulmonary artery in 6 cases. Polyester (Dacron) or pericardial (in the case of infundibular VSD and to preserve the pulmonary valve function) patches were used. The patient with double-outlet right ventricle and restrictive subaortic VSD associated with coarc- tation and hypoplastic aortic arch and left atrial isomerism underwent VSD enlargement followed by an intracardiac baffle repair. A patient with type A IAA who had the biventricular repair abandoned intraoperatively because of Swiss cheese-type VSDs and instead underwent pulmonary artery banding was also included in the study group. A patient with an associated aortic valve stenosis required a concomitant commissurotomy. The associated aortopulmonary window was closed by means of a pericardial patch. A left pulmonary artery arising from the aorta was reimplanted in 1 case. Delayed sternal closure was necessary in 21 cases.

During the study period the concomitant VSD and coarctation repairs were performed in 5 other infants beyond the neonatal period ( 3 of them were 2 months old, 1 was 3 months old, and 1 was 4 months old) by pulmonary autograft patch augmentation.

\section{Data Analysis}

Perioperative data were collected by retrospective review of patient records. Medical records, echocardiographic and cardiac catheterization data, and operative notes were all reviewed. Early survivors were considered to be patients who were discharged alive from the hospital and survived at least 30 days from the time of repair. Recurrent arch obstruction was defined as a resting systolic pressure gradient greater than $20 \mathrm{~mm} \mathrm{Hg}$ during catheterization. Follow-up was carried out by means of physician contact with each patient and was based on clinical and echocardiographic data. Time-related events were examined by actuarial methods. Comparisons between time-related events were performed with the log-rank test. Ratios were expressed with 70\% CIs. To compare the three groups, the $t$ test was used for continuous variables and the $\chi^{2}$ test was used for dichotomous variables.

\section{Results \\ Early Results}

There were 3 early deaths among the 54 patients $(6 \%, 70 \% \mathrm{CI}$ $2 \%-11 \%$ ). One patient with IAA died of RSV pneumonia. The second patient with coarctation and VSD died after an early reoperation for supravalvular aortic stenosis. The third patient with coarctation and VSD had a perioperative myocardial infarction develop; he underwent urgent heart transplantation, and multiple organ failure was the cause of death.

One patient with IAA and right aortic arch could not be weaned from mechanical ventilation because of right bronchial compression. He underwent a reoperation in which an aortopexy was performed through a right thoracotomy. At discharge all the patients were evaluated by echocardiography. Only 1 patient showed significant gradient at the level of the reconstructed aortic arch, and the mean gradient was $8 \pm 12 \mathrm{~mm} \mathrm{Hg}$.

\section{Late Results}

The 51 survivors were analyzed in 3 groups according to the arch repair technique. A median follow-up of 29 months (range 3 months-9 years, median 41 months for group I, median 18 months for group II, and median 9 months for group III) was achieved for $100 \%$ of survivors as of 


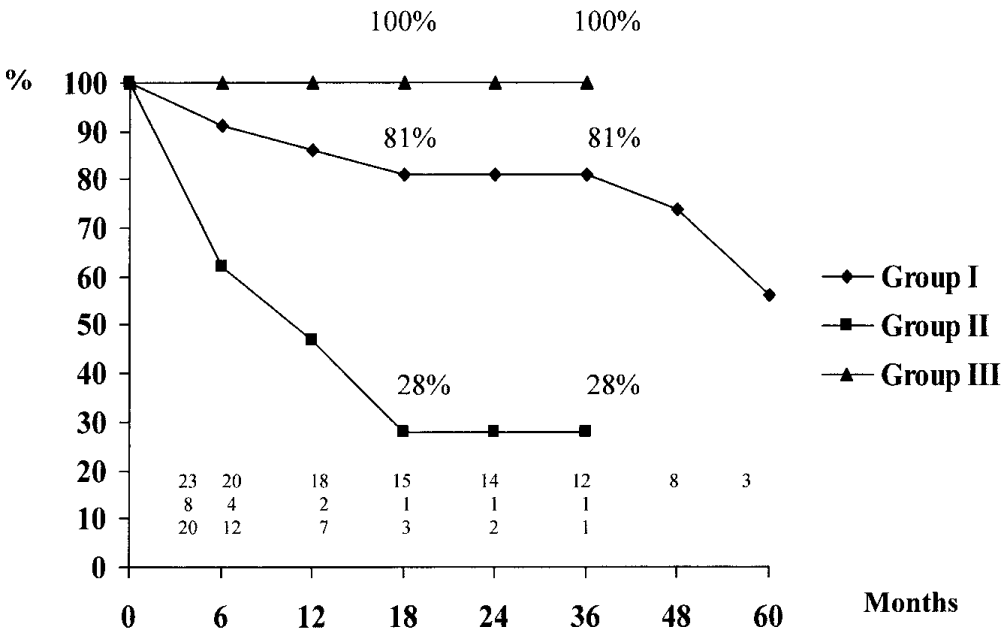

Figure 2. Actuarial freedom from recurrent arch obstruction for groups I (diamonds), II (squares), and III (triangles).

TABLE 2. Reoperations

\begin{tabular}{lcccc}
\hline & $\begin{array}{c}\text { Group I } \\
(\mathbf{n}=\mathbf{2 3})\end{array}$ & $\begin{array}{c}\text { Group II } \\
(\mathbf{n}=\mathbf{8})\end{array}$ & $\begin{array}{c}\text { Group III } \\
(\mathbf{n}=\mathbf{2 3})\end{array}$ & $\begin{array}{c}\text { Total } \\
(\mathbf{n}=\mathbf{5 4})\end{array}$ \\
\hline Total patients & 23 & 8 & 20 & 51 \\
Recurrent arch obstruction* & 5 & 6 & 0 & 11 \\
$\quad$ Surgery & 1 & 2 & 0 & 3 \\
$\quad$ Balloon angioplasty & 4 & 4 & 0 & 8 \\
Left ventricular outflow tract & 2 & 2 & 1 & 5 \\
$\quad$ obstruction & & & &
\end{tabular}

Group I underwent repair by direct anastomosis, group II with a pulmonary homograft patch $(n=4)$ or a xenopericardial patch $(n=4)$, and group III with a pulmonary autograft patch.

${ }^{*} P=.03$ for group III versus group I and $P<.0001$ for group III versus group II.

February, 1, 2001. There were 2 noncardiac late deaths (4\%, 70\% CI 1\%-9\%): 1 patient with IAA died 18 months after the operation of persistent pulmonary hypertension and bronchitis related to inhalation pneumonia, and 1 patient with IAA was operated on because of complex urinary malformations and died after that operation.

\section{Reoperations}

Eleven patients underwent 18 reoperations. There were 11 cases of recurrent aortic arch obstruction managed by surgery $(\mathrm{n}=3)$ or balloon angioplasty $(\mathrm{n}=8)$ at a median delay of 7 months (range 2-51 months, 22\%, 70\% CI 15\%$29 \%$; Table 2). For 2 of the patients for whom the recurrence relief was performed surgically, the principal cause for reoperation was residual VSD in 1 case and subaortic stenosis in the other. The technique of pulmonary autograft aortoplasty was associated with no recurrent coarctation $(P=.03$ for group III vs group I and $P<.0001$ for group III vs group II). At a median follow-up of 29 months (range 3 months-9 years), actuarial freedoms from recurrent arch obstruction were $81 \%$ (70\% CI 66\%-88\%) in group I, 28\% (70\% CI 9\%$50 \%$ ) in group II, and $100 \%$ in group III (Figure 2). The incidences of recoarctation were similar after coarctation and IAA repairs: $26 \%(70 \%$ CI $16 \%-39 \%)$ after coarctation repair versus $21 \%$ (70\% CI 13\%-38\%) after IAA repair. One patient had pulmonary stenosis develop as a result of xenopericardial patch retraction and underwent reoperation at a delay of 8 months. Five patients underwent 8 reoperations because of left ventricular outflow tract obstruction, including 4 subaortic stenosis resections, 1 modified Konno procedure, and 3 Ross-Konno procedures.

\section{Patient Status}

At last visit all survivors were free of symptoms. Echocardiography showed a mean gradient of $10 \pm 10 \mathrm{~mm}$ $\mathrm{Hg}$ at the level of the aortic arch. A residual significant pressure gradient was observed in 2 patients who had already undergone balloon angioplasty for recurrence after direct anastomosis. The patient for whom the pulmonary artery was reconstructed without patch interposition had a pulmonary stenosis develop, with a maximal gradient of 80 $\mathrm{mm} \mathrm{Hg}$ according to echocardiography. All remaining patients for whom the pulmonary artery reconstruction was performed with a fresh pericardial patch showed normal pulmonary valve function, without any pressure gradient or regurgitation. One other patient with hypoplastic aortic valve anulus will eventually require a reoperation because of a transvalvular gradient of $75 \mathrm{~mm} \mathrm{Hg}$. The 5 additional patients who underwent pulmonary autograft patch aorto- 
plasty beyond the neonatal period were also free of symptoms without any significant gradient.

\section{Discussion}

The first single-stage repair of type A IAA was reported by Barratt-Boyes and associates ${ }^{16}$ in 1970. Early diagnosis and preoperative resuscitation through the use of prostaglandins have reduced postnatal mortality and increased the number of candidates for surgical treatment. Finally, improvements in neonatal cardiopulmonary bypass, myocardial protection, and surgical technique permitted the routine singlestage management of aortic arch obstruction associated with intracardiac defects. During the last decade several groups have reported low mortalities and satisfactory clinical outcomes. ${ }^{1-5,9}$ At present many groups advocate the advantages of single-stage relative to staged management. Nevertheless, the staged approach remains indicated for conditions such as the presence of severe multiple VSDs, neurologic disorders, and multiple organ failure.

The aortic arch repair technique has also evolved with time. The most severe forms of arch hypoplasia are now currently treated through sternotomy. Debate persists, however, and although direct anastomosis appears to be preferred by most authors, no technique has proved its superiority. The extensive mobilization of the descending aorta allows the performance of a direct anastomosis in almost all cases, but the tension on the suture line and the presence of residual ductal tissue can result in a considerable rate of recurrence (5\% to $25 \%$ in recent reports). ${ }^{5-8}$ The mechanism appears to be multifactorial and related to the stretching, resulting in diminution of effective vascular diameter and loss of the aortic wall's elasticity and potential for growth. One should also consider that previously reported series included patients beyond the neonatal period in most instances; these cases probably presented less surgical challenge and carried the potential for superior outcome. In this report only neonates and 4 additional infants with ductus-dependent descending aortic perfusion were studied. The aim was to form a homogeneous cohort of patients with complex disease. The observed rate of recurrence after direct anastomosis was similar to those in other experiences (19\%). No predictive factor for recurrence after this technique was revealed.

Bronchial compression is a rare but consistent complication observed after large conduit interposition and also direct anastomosis. It may result from excessive tension between the two aortic ends. ${ }^{1,17}$ Also, the connection of the descending aorta proximally in the ascending aorta to diminish the tension and to perform a larger anastomosis can cause bronchial compression. In our series 1 patient who underwent repair of type B IAA with right descending aorta by means of direct anastomosis had right bronchial compression develop. Diagnosis was made by fibroscopy.
Both tension and the relatively proximal location of the anastomosis were responsible. Weaning from mechanical ventilation was possible after an early reoperation in which an aortopexy through right thoracotomy was performed. One other inconvenience of the direct anastomosis technique is its limitation in case of the need for ascending aorta augmentation, which is not uncommon in the studied subgroup of patients.

The enlargement of the aortic arch by means of a patch constitutes a valuable alternative to primary anastomosis. This technique was proposed with the aim of complete relief of anatomic afterload and a tension-free anastomosis. It was frequently combined with resection and end-to-end anastomosis. Most published series have suggested the use of homograft patches. ${ }^{2,4,5}$ Several reports have presented low rates of recurrence. ${ }^{4,10}$ In this series 8 patients had endto-end repair associated with homograft $(\mathrm{n}=4)$ or xenopericardial $(n=4)$ patch augmentation: 6 required reoperation for recurrence, 3 after homograft patches and 3 after xenopericardial patches. Recurrence may be due to rheologic as well as immunologic factors. Although synthetic (polytetrafluoroethylene or polyester) patches have also been presented as an ideal solution, the technical difficulties of inserting a synthetic patch in a neonate and the constant risk of late aneurysm formation have been enough for that to be abandoned as an alternative. ${ }^{11}$

Balloon angioplasty for aortic recoarctation after surgical repair has become the method of choice during the past decade. Long-term data are still minimal, however, and the procedure is not free of complications. ${ }^{18,19}$ In addition, in the particular subset of patients studied here the recurrence was often extremely proximally situated, making the angioplasty procedure challenging and an eventual stenting impossible. Thus balloon angioplasty for recurrence after neonatal surgical treatment of IAA or severe coarctation through sternotomy might have a relatively poor outcome: among the 8 patients who required balloon angioplasty for recurrence, 2 have already undergone a second angioplasty procedure and 2 had significant residual gradients.

There are several limitations to this study. First, it is a retrospective analysis. In addition, there is a potential for patient selection bias. All patients who underwent pulmonary autograft patch repair were operated on during the last 3 years. Standardized techniques were used in all cases, however, and the selection of a highly homogeneous study cohort was intended to limit the potential for bias.

One of the major controversies regarding the use of the pulmonary autograft patch is the eventual deterioration of the pulmonary valve. The patient population presented here had hypoplastic left heart aorta complex in a majority of cases and there were 18 patients with a subaortic narrowing to less than a $\mathrm{Z}$ score of $-6 .^{2}$ Three patients had already undergone a Ross or Ross-Konno procedure, and there will 


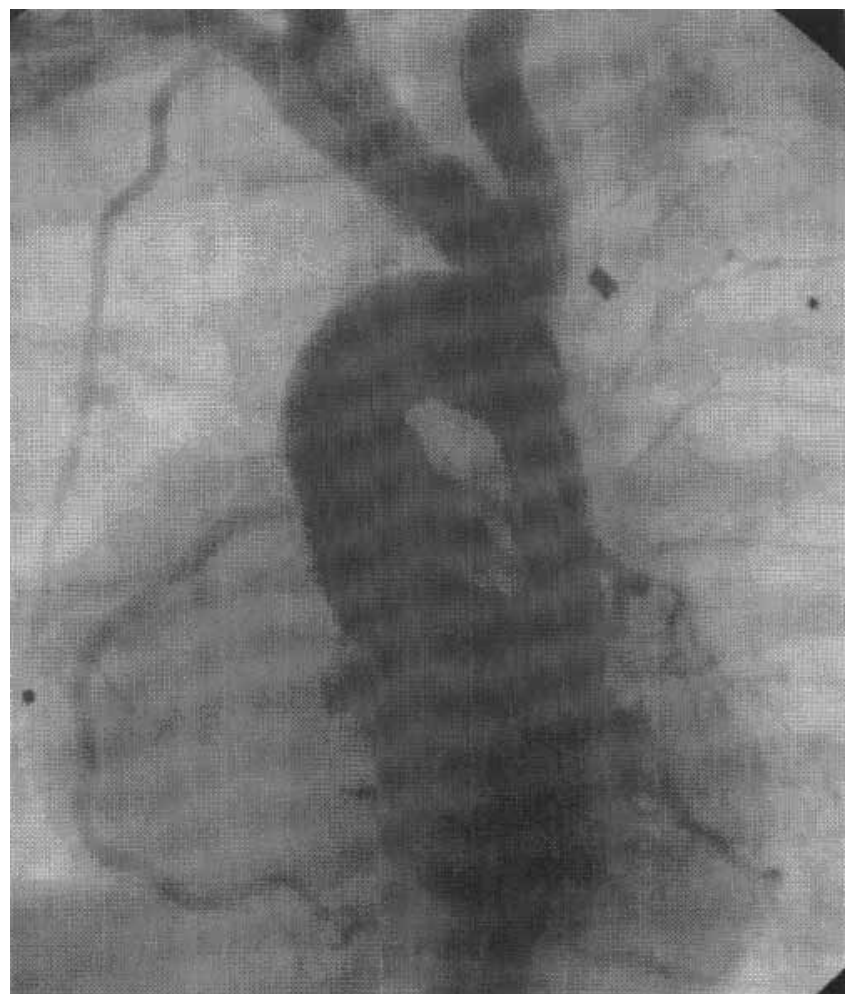

Figure 3. Left ventricle-aorta angiography of patient with neonatal type B IAA repair by means of pulmonary autograft patch augmentation of ascending aorta and anastomosis, with subaortic narrowing of $3.5 \mathrm{~mm}$ ignored at operation, at 1 year of age, before Ross-Konno procedure.

certainly be at varying delays other candidates for such a procedure. ${ }^{2,6}$ Because we used fresh autologous pericardium as substitute, we did not observe pulmonary valve dysfunction on echocardiography. It is true that in 1 case of neonatal type B IAA repair by means of pulmonary autograft patch augmentation of the ascending aorta and the anastomosis, the subaortic narrowing $(3.5 \mathrm{~mm})$ was ignored. At a delay of 6 months this patient required relief of a subaortic stenosis by myectomy. He had a recurrence of the subaortic obstruction, and a Ross-Konno procedure was performed at 14 months of age (Figure 3 ). The pulmonary valve and its postoperative function in the aortic position were normal.

In conclusion, aortic arch repair associated with pulmonary autograft patch augmentation results in superior midterm outcomes and constitutes a reliable alternative to the direct anastomosis technique. It permits complete relief of anatomic afterload and diminishes the anastomotic tension, thus reducing the risk of restenosis and tracheobronchial compression. We observed a significantly higher rate of recurrence after patch aortoplasty with homograft and pericardial patch augmentation. ${ }^{20}$

\section{References}

1. Karl TR, Sano S, Brawn W, Mee RB. Repair of hypoplastic or interrupted aortic arch via sternotomy. J Thorac Cardiovasc Surg. 1992;104:688-95.

2. Jonas RA, Quaegebeur JM, Kirklin JW, Blackstone EH. Outcomes in patients with interrupted aortic arch and ventricular septal defect. $J$ Thorac Cardiovasc Surg. 1994;107:1099-113.

3. Sandhu SK, Beekman RH, Mosca RS, Bove EL. Single-stage repair of aortic arch obstruction and associated intracardiac defects in the neonate. Am J Cardiol. 1995;75:370-3.

4. Tchervenkov CT, Tahta SA, Jutras L, Beland MJ. Single stage repair of aortic arch obstruction and associated intracardiac defects with pulmonary homograft patch aortoplasty. J Thorac Cardiovasc Surg. 1998;116:897-904.

5. Gaynor JW, Wernvsky G, Rychik J, Rome JJ, DeCampi WM, Spray TL. Outcome following single-stage repair of coarctation with ventricular septal defect. Eur J Cardiothorac Surg. 2000;18:62-7.

6. Serraf A, Lacour-Gayet F, Robotin M, Bruniaux J, Sousa-Uva M, Roussin R, et al. Repair of interrupted aortic arch: a ten-year experience. J Thorac Cardiovasc Surg. 1996;112:1150-60.

7. Sell JE, Jonas RA, Blackstone EH, Kirklin JW. Castaneda AR. The results of a surgical program for interrupted aortic arch. J Thorac Cardiovasc Surg. 1988;96:864-77.

8. Sano S, Brawn WJ, Mee RB. Repair of truncus arteriosus and interrupted aortic arch. J Cardiac Surg. 1990;5:157-62.

9. DeLeon S, Downey F, Baumgartner N, Ow P, Quinones J, Torres L, et al. Transsternal repair of coarctation and associated cardiac defects. Ann Thorac Surg. 1994;58:179-84.

10. Vitullo DA, DeLeon SY, Graham LC, Eidem BW, Roughneen PT, Javorski JJ, et al. Extended end to end repair and enlargement of the entire arch in complex coarctation. Ann Thorac Surg. 1999;67:528-33.

11. Bromberg B, Beekman RH, Rocchini AP, Snider AR, Bank ER, Heidelberger K, et al. Aortic aneurysm after patch aortoplasty repair of coarctation: a prospective analysis of prevalence, screening tests and risks. J Am Coll Cardiol. 1989;14:734-41.

12. Celoria G, Patton R. Congenital absence of the aortic arch. Am Heart J. 1959;58:407-13.

13. Conte S, Lacour-Gayet F, Serraf A, Sousa-Uva M, Bruniaux J, Touchot A, et al. Surgical management of neonatal coarctation. $J$ Thorac Cardiovasc Surg. 1995;109:663-74.

14. Rajasinghe HA, Reddy VM, van Son JA, Black MD, McElhinney DB, Brook MM, et al. Coarctation repair using end-to-side anastomosis of descending aorta to proximal aortic arch. Ann Thorac Surg. 1996;61:840-4.

15. Tchervenkov CL, Korkola SJ, Shum-Tim D. Surgical technique to avoid circulatory arrest and direct arch vessel cannulation during neonatal aortic arch reconstruction. Eur J Cardiothorac Surg. 2001;19:708-10

16. Barratt-Boyes BG, Nicholls TT, Brandt PW, Neutze JM. Aortic arch interruption associated with patent ductus arteriosus, ventricular septal defect, and total anomalus pulmonary venous connection. J Thorac Cardiovasc Surg. 1972;62:367-73.

17. Lacour-Gayet F, Serraf A, Galletti L, Bruniaux J, Belli E, Piot D, et al. Biventricular repair of conotruncal anomalies associated with aortic arch obstruction. Circulation. 1997;96 Suppl II:II328-34.

18. Lock JE, Bass JL, Amplatz K, Fuhrman BP, Castaneda-Zuniga W. Balloon dilation angioplasty of aortic coarctations in infants and children. Circulation. 1983;68:109-16.

19. Siblini G, Rao PS, Nouri S, Ferdman B, Jureidini SB, Wilson AD. Long-term follow-up results of balloon angioplasty of postoperative aortic recoarctation. Am J Cardiol. 1998;81:61-7.

20. Serraf A, Roussin R, Belli E, Zoghbi J, al Chare W, Aupecle B, et al. [Enlarging angioplasty of the aortic arch with an pulmonary artery autograft patch: interest in a single-stage repair of the syndrome of coarctation and interruption of the aortic arch]. Arch Mal Coeur Vaiss. 2001;94:433-8. 


\section{Discussion}

Dr J. William Gaynor (Philadelphia, Pa). I congratulate Roussin and colleagues for their study describing an innovative technique for arch reconstructions in infants with aortic arch obstruction and either coarctation or interruption of the aortic arch. Particularly for patients with coarctation and VSD, there is an ongoing debate concerning the optimal management strategy. A multi-institutional study sponsored by the Congenital Heart Surgeons Society suggested that survival was greatest with a staged approach, with initial coarctation repair and pulmonary artery banding followed by delayed VSD closure. However, there are potential significant advantages to correction of all hemodynamic abnormalities at the initial operation with no obligate need for reoperation. Advocates of the staged approach have suggested that such a strategy is associated with a lower mortality, a lower incidence of recurrent arch obstruction, and avoidance of the need for deep hypothermic circulatory arrest during the arch reconstruction.

This study and recent reports from other institutions, including our own, have demonstrated that a single-stage strategy can be accomplished with low mortality and an acceptable incidence of recurrent arch obstruction. With the use of isolated cerebral perfusion, such as Roussin and colleagues describe, there is no need for circulatory arrest during the arch reconstruction.

Unfortunately, there are few long-term follow-up data for either of these strategies, especially in terms of hypertension, ventricular dysfunction, and neurodevelopmental outcome. In addition, as Roussin and colleagues note and other studies have confirmed, subaortic narrowing is common. Even after successful repair, these patients are at risk for development of additional levels of left ventricular outflow tract obstruction, particularly subaortic stenosis. We have found, as did Roussin and colleague, a significant incidence of reintervention for other levels of left ventricular outflow tract obstruction, often within a few years of the original operation. Many children eventually require a Ross-Konno procedure for complex left ventricular outflow tract obstruction. Thus, although the approach described here is attractive, potential damage to the pulmonary valve is a major concern with this technique.

I have several questions. First, the use of isolated cerebral perfusion during arch reconstruction is an appealing and increasingly popular technique; however, there are few data concerning longterm neurodevelopmental outcomes with this technique. Have you formally investigated the neurodevelopmental outcomes among your patients?

Second, in the article you noted that most VSDs were closed through a right ventriculotomy. These VSDs are usually accessible with an approach across the tricuspid valve, so why was a ventriculotomy used?

Third, although you noted that 1 patient underwent a successful Ross procedure, you did not provide data concerning the incidence of pulmonary artery distortion and pulmonary insufficiency among these patients, which is obviously going to be important in the long term. Have you formally evaluated the function of the pulmonary valve in all of your patients?

Finally, given the significant incidence of subaortic narrowing and the need for reintervention for subaortic stenosis, is there a subset of these patients for whom a neonatal Ross-Konno procedure should be performed as part of the initial repair?
Dr Belli. Concerning the isolated perfusion of the brachiocephalic trunk, Dr Gaynor, unfortunately at present we do not have any data about the neurologic development of those children. This aspect can be evaluated by a randomized comparative series. The isolated cerebral perfusion was performed under conditions that were not far from total circulatory arrest technique, with the temperature being under $25^{\circ} \mathrm{C}$, usually $20^{\circ} \mathrm{C}$. We tried to have the highest flow, which was almost always between $30 \%$ and $50 \%$ of the theoretic perfusion flow, and arterial blood pressure monitoring in the right radial artery permitted us to maintain a pressure between, again, 30 and $50 \mathrm{~mm} \mathrm{Hg}$. The perioperative serum lactate levels appeared significantly inferior with selective perfusion of the brachiocephalic trunk.

With respect to the right ventriculotomy approach, this is our preferred approach for those anomalies at Marie Lannelongue Institute: we often perform the VSD closure in the neonatal period through right ventriculotomy, particularly in the presence of conoventricular malalignment VSDs. The right atriotomy approach can require more traction, can take more time, and can be challenging with the bicaval cannulation and continuous perfusion technique that we use. It can also result in tricuspid valve distortion. In addition, we did not observe any negative effects of those limited right ventriculotomies on early and late outcomes; this information was already reported.

Concerning the pulmonary valve function, I did not mention that after echocardiographic evaluation the pulmonary valve function was found normal in all patients who received the fresh pericardial patch. One patient has already undergone a Ross-Konno procedure 1 year after the pulmonary autograft patch repair. At the beginning of the experience 2 patients had xenopericardial patch closure of the pulmonary defect, and 1 required a reoperation because of the shrinkage of this patch, but pulmonary valve function was not deteriorated. The second also had a gradient, which is now more than $40 \mathrm{~mm} \mathrm{Hg}$.

In this series we had only 1 patient who had a Ross-Konno procedure associated with arch repair and VSD closure. As far as I know this is the only patient who underwent a primary neonatal Ross-Konno procedure for IAA associated with severe subaortic stenosis. Our present policy is to perform the conventional biventricular repair even in presence of a severe narrowing of the subaortic region. This is rarely associated with subaortic myectomy because of the anatomy and the surgeon's preference. With increasing experience, the neonatal Ross procedure will probably have larger application in this field.

Dr Christo I. Tchervenkov (Montreal, Quebec, Canada). I rise in defense of the single-stage approach for cardiac defects with aortic arch obstruction and in defense of the pulmonary homograft patch aortoplasty. I would also like to recognize the contributions of your group at Marie Lannelongue Hospital in the surgical treatment of this challenging group of patients. I am glad to see that the debate in the last 10 years has shifted away from whether to adopt a single-stage approach and toward which is the optimal surgical technique for the aortic arch repair and whether to use circulatory arrest.

Three years ago at the annual meeting of the Association for Thoracic Surgery we presented our experience at Montreal Children's Hospital with a single-stage approach of intracardiac and 
concomitant aortic arch repair with pulmonary homograft patch aortoplasty in 40 patients with a 5\% early mortality. Most patients in our series had transposition complexes and hypoplastic left heart complex with arch obstruction. Currently for more than 50 patients the mortality is under $4 \%$ and the freedom from reintervention for recoarctation is approximately $95 \%$, despite the fact that our surgical technique rarely includes excision of the coarctation shelf.

I believe that your group II, composed of only 8 patients and with two different patch materials used, is just too small for any meaningful comparison with the other groups. Furthermore, your unfavorable experience with only 4 patients with pulmonary homograft patch aortoplasty is clearly insufficient to discard that technique as part of the surgical armamentarium, considering the low recoarctation rate of $8.3 \%$ reported by our group.

Have you used pulmonary autograft patch aortoplasty in patients with transposition complexes, where using the extended end-to-end anastomosis introduces 2 circumferential suture lines, with potential for excessive tension at 2 anastomoses? If not, why not? In our experience we have had no deaths among 22 patients with transposition complexes and aortic arch obstruction undergoing a single stage-arterial switch operation and aortic arch repair.

Dr Belli. I want to make one point clear concerning the singlestage versus staged discussion. It is obvious that most of the patient population of the study fall outside this discussion. There were 24 patients with IAA type B and 3 with type $C$. There were 24 patients with coarctation, which was associated, at least in 18 cases, with severe hypoplasia of the entire arch. The presence of preoperative subaortic stenosis was documented in 18 cases. If we were to analyze the patients singly, we could certainly find some candidates adapted to staged management. Essentially, however, the discussion of single-stage versus staged is excluded for this particular patient population.

Concerning the homograft patch enlargement, I agree that we have only a small group of patients, which does not allow us to make a valuable conclusion. There were 8 patients who had biologic patches: 4 xenopericardial and 4 homograft patches. From both small groups, 3 had recoarctation. I believe that the outcome of aortic arch repair with homograft patches is not free from recoarctation, although it is not so dramatically poor. We perform this technique preferentially in cases of transposition of the great arteries, truncus arteriosus associated with IAA, and some other conotruncal anomalies. Unfortunately, the rate of recoarctation has not been as good as that reported in your series; it is around $15 \%$ to $20 \%$. However, one should not forget that the population studied here consisted exclusively of neonates. Independent of the technique used, we did not observe recurrence in infants beyond the neonatal period.

With respect to the homograft patch enlargement in the transposition setting, as François Lacour-Gayet has reported at the American Heart Association meeting, in our current practice we almost always use homograft patch enlargement to adjust the two new aortic ends. We have not developed our new technique to obtain a pulmonary autograft patch, which in this condition must be relatively large.

Dr Thomas L. Spray (Philadelphia, $\mathrm{Pa}$ ). This is an interesting technique. What do you think the mechanism is that makes this fundamentally better than using another patch? Why not use native pericardium if you think that viability is an issue? When you do this, you end up putting native pericardium in the pulmonary artery, which you then may have to use for a Ross-Konno operation in the future, so now part of the aorta is native pericardium anyway. Why not use unfixed native pericardium and have viability and potentially fewer problems with stenosis?

Dr Belli. I appreciate your question, but I am afraid that I do not have any data to answer it.

Dr Spray. Do you think that is fundamentally better because it is living tissue?

Dr Belli. Fundamentally, first we have the surgical comfort of the biologic patch material to implant. Second, it is living arterial wall tissue with the potential for growth. However, the main reason was the stability of the initial result at follow-up, with absence of the risk of patch shrinkage and a risk of the other major complication, which is late aneurysm formation, that must be trivial if not zero. 